\title{
Je predlagano število pokrajin primerna zasnova za uravnotežen regionalni razvoj?
}

\author{
UDK: 353 712(497.4) \\ Janez Zore \\ Mestna občina Novo msto \\ janez.zore@novo.mesto.si
}

\section{IZVLEČEK}

Stopnja regionalnega razvoja posameznih regij je zelo različna. Ključna dejavnika na tem področju sta inovativna družba in njena tehnološka razvitost. Globalni trendi narekujejo skokovite spremembe na gospodarskem področju, ki jim ni in ni videti konca. Nove tehnologije se tu izkažejo za uspešno vez družbe s hitro razvijajočim se trgom. Temelj gospodarsko najbolj razvitih družb je učinkovito malo gospodarstvo. To znatno pripomore k razvoju regije in gospodarskega okolja, zato so vse pobude za njegovo pospeševanje dobrodošle in hkrati nujne. Malo gospodarstvo je treba upoštevati kot vir novih delovnih mest, tehnološkega razvoja in dviga konkurenčnosti tako regij kot tudi države. Vlada se mora pri določitvi števila pokrajin odločiti po treznem premisleku. Strateška odločitev ne sme biti rezultat političnega konsenza, pač pa mora izražati konkretne cilje, ki jih prinaša ustanovitev druge ravni lokalne samouprave. Strokovnjaki opozarjajo na prežeče nevarnosti, zadnjo besedo pa bo ponovno imela politika.

Ključne besede: regionalizem, regionalni razvoj, decentralizacija, pokrajine, inovacije, tehnološki parki.

\section{Uvod}

Vse države se soočajo z neenakomerno razvitim ozemljem, zato se regije med seboj $\vee$ marsičem razlikujejo. Vpliv na različne razvojne možnosti določenega območja se kaže predvsem $v$ različni razpoložljivosti naravnih, gospodarskih, socialnih in drugih virov. Zmanjševanja regionalnih razlik ne moremo prepustiti le zakonitostim trga, saj jih ta le še povečuje. Vsaka sodobna država si prizadeva za odpravljanje regionalnih neravnovesij na svojem ozemlju in krepi ekonomsko in socialno povezanost. $\vee$ ta namen države izvajajo svojo lastno regionalno politiko, v okviru katere spodbujajo skladnejši regionalni razvoj svojega gospodarstva. 


\section{Janez Zore \\ Je predlagano število pokrajin primerna \\ zasnova za uravnotežen regionalni razvoj?}

\section{Regionalizem in namen regionalizacije}

Smotrna uporaba regionalnih virov (naravnih oz. okoljskih, gospodarskih, infrastrukturnih, človeških) je po mnenju Pluta (1999, str. 65) eden izmed temeljev skladnejšega regionalnega razvoja. Okolju in regionalni pripadnosti ljudi prilagojena prostorska členitev države je pogoj za okoljsko, gospodarsko, kulturno in socialno uravnotežen regionalni napredek. Členitev prostora državnega ozemlja tudi z upoštevanjem naravnogeografskih značilnosti (naravne regije, bioregije oz. ekoregije, ekodistrikti, porečja, okoljski prostor) je ena izmed osnov za okolju primerno organizacijo življenja in dela na regionalni ravni.

Koncept regionalizacije ima vire $v$ geografski in prostorsko-planski terminologiji. Je rezultat kompleksnega in primarno ekonomskega, ekološkega in infrastrukturnega planiranja določenega dela teritorija. Svet Evrope $\vee$ svojem poročilu' opredeljuje regionalizacijo kot skupek usklajenih politik, ki jih vodijo centralna vlada ali njihovi oddelki, lahko pa tudi decentralizirane regionalne oblasti, ki ustvarjajo svoje učinke na območju, manjšem, kot je država, na ozemlju regionalne enote. Regionalizacija ne pomeni nujno tudi prenosa moči, funkcij ali avtonomije na regionalno oblast in ji tako omogočiti prakticiranje podeljevanja moči. Za države $v$ tranziciji, ki so članice ali bodo prihodnje članice Evropske Unije ( $v$ nadaljevanju EU), je lahko regionalizacija prav tako rezultat prilagajanja zahtevam EU, ki so eden izmed pogojev za vstop $\vee$ EU.

Konec osemdesetih in $v$ začetku devetdesetih let prejšnjega stoletja je regionalna raven ponovno začela pridobivati na pomenu. To je bilo obdobje, ko so se začela porajati razmišljanja o "Evropi regij". V zadnjih desetletjih naj bi torej $\vee$ državah članicah EU številni in raznovrstni dejavniki čedalje bolj vplivali na regionalno komponento oblikovanja in izvajanja javnih politik (Keating v: Lajh, 2006, str. 23), regionalna komponenta pa naj bi hkrati pridobivala vedno večji pomen. Tak razvoj kaže, da regionalne politike držav članic EU in držav kandidatk oziroma držav pristopnic EU postajajo vedno bolj vpletene $v$ evropsko okolje oblikovanja in izvajanja, politike na nacionalni ravni pa postajajo vedno bolj regionalizirane (Lajh, 2006, str. 23-24).

$\checkmark$ večini evropskih držav prenaša država na občine in druge lokalne skupnosti del svojih pristojnosti, kadar ocenjuje, da je na ta način mogoče

1 Draft Report on the current situation concerning regionalization and the prospects for developing regional self-government in Council of Europe member states. Strasbourg, 2006. 
učinkoviteje uresničevati posamezne zadeve, bolj upoštevati specifičnosti nekega območja ali približati upravo prebivalcem. Svet Evrope ugotavlja, da v številnih evropskih državah poteka proces reformiranja ali uvajanja regionalne samouprave in da obstaja pestra paleta modelov in oblik regionalne samouprave $\vee$ Evropi, kar izvira iz različne ustavne tradicije ter socio-ekonomskih, kulturnih in geografskih razmer, ki so specifične za vsako državo. Vendar pa je mogoče prevzeti temeljne koncepte in načela, ki so skupni za vse modele regionalne samouprave (Vlaj, 2006a, str. 10-11). V globalizacijskem obdobju in zaradi vstopa Slovenije v EU je po mnenju Strmšnika (v: Ravbar, 1999, str. 102) za konkurenčen nastop na notranjem evropskem trgu potrebno združevanje slovenskih regij. Majhne in ekonomsko šibke slovenske regije bi kaj hitro potegnilo $\vee$ gravitacijska območja in interesne sfere velikih razvojnih polov $\vee$ soseščini. Evropska strukturna politika z graditvijo panevropskih omrežij in uveljavljanjem pravil prostega trga to smer razvoja celo spodbuja. Regionalna politika je eno redkih področij ekonomske politike, ki z vstopom v EU ni izgubilo suverenosti, tako da še vedno ostaja $\vee$ pristojnosti nacionalnih držav. Decentralizirana in med različne teritorialne ravni odločanja razpeta regionalna politika tej nalogi zagotovo ne bi bila dorasla.

Za našo državo je značilno, da je bilo od vsega začetka, ko so se oblikovale prve predstave o lokalni samoupravi, najbolj nejasno in najbolj sporno vprašanje, ali potrebujemo $v$ prostoru med državo in občinami še eno teritorialno enoto in kakšna naj bi bila ta enota, kakšna naj bi bila njena narava in njen položaj v sistemu države oziroma lokalne skupnosti; ali je treba po obsegu majhno državo notranje razčlenjevati - razen na občine - še na eno teritorialno raven s statusom samoupravne skupnosti, kot jo imajo praviloma druge evropske in druge države, razen najmanjših državic (npr. Luksemburg, Malta) (Šmidovnik, 2004, str. 11). Vzpostavljena teritorialna ureditev Slovenije je tesno povezana s problemom institucionalnega primanjkljaja na medobčinski oziroma regionalni ravni. Tako je $v$ vmesnem prostoru med državno upravo in lokalno samoupravo nastal vakuum, ki po mnenju mnogih negativno učinkuje na delovanje tako nacionalne kot tudi lokalne ravni. Dejstvo je, da se zadeve, ki izhajajo iz skupnih interesov na nekem lokalnem ozemlju, ne ustavijo na mejah njihove občine, temveč gredo preko njih na širše teritorialne enote (Šmidovnik v: Lajh, 2006, str. 173).

Regionalizacija oziroma ustanovitev pokrajin je, kot navaja Vlaj (2005), potrebna predvsem zaradi hitrejšega reševanja notranjih razvojnih problemov ter uveljavljanja načela subsidiarnosti oziroma zagotovitve procesa decentralizacije 


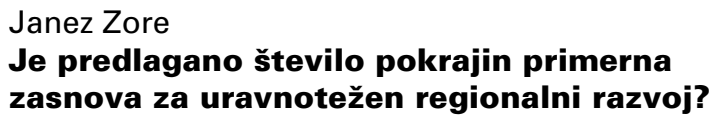

kot podlage za hitrejši in skladnejši razvoj celotne Slovenije. Potreba po regionalizaciji izhaja tudi iz sprememb, do katerih je prišlo v obdobju po uveljavitvi lokalne samouprave; povečalo se je število občin, spremenila se je njihova struktura, prišlo je do centralizacije njihovih pristojnosti (razen pristojnosti lokalnega pomena) in do poglabljanja razlik $\vee$ stopnji gospodarske razvitosti posameznih območij naše države. Tako naj bi pokrajine zapolnile vrzel med majhnimi občinami in državo ter blažile sedanjo preveliko urejevalno in dejansko moč države $v$ odnosu do šibkih občin. Povezovale naj bi tudi občine, saj bi učinkoviteje urejale in izvajale potrebe državljanov in gospodarstva, ki sedaj presegajo zmogljivosti posamezne občine. Pokrajine so $\vee$ Sloveniji potrebne tudi zaradi primerljivosti z državami EU in zaradi uspešnega kandidiranja za sredstva EU in regionalni razvoj (glej tudi Grafenauer, 2000, str. 434).

Pri nas je zaenkrat regionalna raven predvsem funkcionalna, ne pa tudi upravnopravna. Mnogi slovenski strokovnjaki (npr. Ribičič, Plut, Vlaj, Grafenauer v: Lajh, 2006, str. 173) pa menijo, da bi morale biti regije ustanovljene kot upravnopolitične enote, $v$ našem primeru pokrajine. Kot ključni razlog navajajo, da veljavna teritorialna ureditev vse bolj poglablja prepad med majhnimi in šibkimi občinami in centralizirano državo. To pomeni, da je občuten primanjkljaj pokrajin kot upravno-političnih enot, ki bi lahko bile nosilke regionalnega razvoja. Državna uprava je tako organizirana po načelu močnih ministrstev in velikega pomena sektorskih in razvojnih politik (Kavaš et al. v: Lajh, 2006, str. 174). Razvoj lokalne samouprave zato spremlja pretirana centralizacija nalog $\vee$ državi. Tako naj bi pokrajine zapolnile vrzel med majhnimi občinami in državo ter ublažile sedanjo preveliko regulatorno in dejansko moč države $v$ odnosu do občin (Vrišer v: Lajh, 2006, str. 174).

\section{Regionalni odzivi na učinke globalizacije}

$\checkmark$ zadnjih nekaj desetletjih je svetovno gospodarstvo doživelo izjemen razvoj. Države so prešle iz industrijske $v$ informacijsko družbo. Umsko delo je kot prevladujoča dejavnost $v$ veliki meri nadomestilo fizično delo. Za sodobni svet so značilne hitre spremembe, pospešen znanstveni in tehnološki razvoj in velika tekmovalnost. Takšen razvoj ustvarja zahteve po višjih ravneh izobraževanja in učenja. Ni pa splošno znano, da takšen razvoj ustvarja tudi nove psihološke zahteve, ki so posledica sprememb. Natančneje, napredek zahteva večjo sposobnost inovativnosti, samonadzora in osebne odgovornosti, torej višjo raven zavesti pri delu. 


\section{Janez Zore \\ Je predlagano število pokrajin primerna zasnova za uravnotežen regionalni razvoj?}

$\checkmark$ razvitih državah se je regionalizem uveljavil proti koncu 20. stoletja, kasneje pa se je razcvetel tudi gospodarski razvoj na lokalni ravni. Proces je nastal iz občutnih problemov strukturnega prilagajanja lokalnega gospodarstva na spremenjene družbene in gospodarske razmere. Nastali problemi so opozorili, da nacionalne razvojne politike niso in dejansko tudi ne morejo zagotoviti primernega zadovoljevanja lokalnih potreb. Lokalna okolja so postala bolj dejavna. Povečana mobilnost gospodarske dejavnosti, učinki vse večje ekonomske integracije velikih korporacij in izzivi novih oblik konkurence so postavili zahteve za večjo lokalno konkurenčnost okolja, ki bi se sicer izpostavilo nevarnosti izgubljanja gospodarske baze. Okolja, ki so ustvarila spodbude za gospodarski razvoj, so aktivno pripomogla tudi k pospešenemu regionalnemu razvoju (Glas, 2000, str. 95).

Regionalna strukturna politika in skladen regionalni razvoj sta pomembni vodili tako politike EU kot tudi posameznih držav. Med posameznimi regijami znotraj EU in držav članic nastajajo vedno večje razlike. Razvojni učinki se kažejo predvsem $v$ tistih regijah, ki skrbijo za razvoj malega gospodarstva in inovativnosti. Malo gospodarstvo postaja iz leta $v$ leto pomembnejši del tako svetovnega kot tudi slovenskega gospodarstva in je ena najperspektivnejših gospodarskih panog. Spodbujanje njegove rasti je ključno področje ustvarjanja možnosti za nadaljnji gospodarski razvoj. Znatno pripomore pri ustvarjanju novih delovnih mest, obenem pa je eden osnovnih vzvodov za skladnejši regionalni razvoj, saj prinaša nove informacije in znanja ter spreminja miselnost ljudi. Vpliv malega gospodarstva je pomemben predvsem pri razvoju manjših lokalnih območij, ki ne nudijo pravih možnosti za velika podjetja. Za pospeševanje razvoja malih in srednje velikih podjetij države ustanavljajo institucije, ki podpirajo aktivnosti za njihov razvoj, poleg tega pa lahko kot pomoč vzpostavijo še različne vrste ukrepov in mehanizmov. Prilagodljive institucije so nujne za uspešno delovanje in dopolnjevanje potreb podjetij in območij. Partnerji s svojim dolgoročnim združenjem ter povezovanjem razpoložljivih potencialov znatno pripomorejo k uspešnemu in pospešenemu razvoju malih in srednje velikih podjetij. $\vee$ konkretnih okoliščinah je tuje pobude neprimerno posnemati, saj se morajo prilagoditi konkretnim dejavnikom, ki jih ponujajo regionalne značinosti posameznih okolij.

Podjetja oz. podjetniki za svoj razvoj potrebujejo primerne lokacije z urejeno infrastrukturo. Zavedanje lokalne skupnosti in regije je $v$ tem primeru samoumevno, nesporno pa jim je izrazito jasen tudi pomen malih in srednje velikih podjetij. Ti nastopajo $v$ vlogi spodbujevalcev lokalne gospodarske rasti, 
Janez Zore

Je predlagano število pokrajin primerna

zasnova za uravnotežen regionalni razvoj?

so nosilci proračunskih prilivov, zaposlovanja, inovacij, tehnološke prenove ter pospešene investicijske dejavnosti. Da bi lokalne skupnosti pritegnile podjetja, jim skušajo ponuditi urejen prostor s potrebno podjetniško infrastrukturo $v$ obliki poslovnih con, inkubatorjev ali tehnoloških parkov.

\section{Tehnološki parki v vlogi pospeševalcev regionalnega razvoja}

Konkurenca na svetovni ravni prinaša velik tehnološki napredek. Podjetja so se, kot ugotavljajo Marques in drugi (2003, str. 114), prisiljena usmeriti na povečanje produktivnosti s tehnološkega vidika. Zato države in tudi regije pospešujejo nastajanje in si prizadevajo za uspešno delovanje visoko tehnoloških podjetij. $V$ ta namen so članice OECD sprejele številne ukrepe, s pomočjo katerih pripravljajo pogoje za pospešen razvoj in učinkovito podporo pri delovanju novih, inovativnih podjetij. Med temi instrumenti, ki so tudi pomembno orodje regionalnih gospodarskih strategij in dokazano učinkovito pripomorejo k pospešenemu regionalnemu razvoju, so tudi tehnološki parki. Ti nudijo podjetjem $v$ zagonu prostor in svetovalne storitve, hkrati pa tudi velike možnosti za raziskovalno dejavnost. Njihov ključni cilj je pospeševanje skladnega regionalnega razvoja, kar seveda omogoča dohitevanje razvitejših regij skupnega evropskega trga, $\vee$ katerega je Slovenija kot polnopravna članica EU zavedno vstopila.

Dejavnost tehnoloških parkov se je začela razvijati z namenom spodbujanja podjetništva in prenosa raziskovalnih dosežkov in raziskovalne sfere $v$ gospodarstvo. Začetek ustanavljanja znanstvenih in tehnoloških parkov sega $v$ šestdeseta leta prejšnjega stoletja, $v$ južni Evropi pa jih pred sredino osemdesetih skoraj ni bilo. Hitrejši razvoj te oblike podpore za podjetja je nastal ob poglabljanju evropskega integracijskega procesa, saj so tehnološki in znanstveni parki omogočali pridobivanje evropskih razvojnih sredstev, obenem pa so prispevali $k$ lajšanju industrijskega razlikovanja in pospešitvi regionalnega razvoja. Ta ima velik vpliv na razvoj lokalnega podjetništva. Uspešen razvoj podjetništva se pogosto povezuje z razvojem lokalnih finančnih institucij. Na razvoj podjetništva vpliva tudi posnemanje dobrih zgledov $v$ lokalnih okoljih, saj tujim zgledom napoti stojijo razne kulturne zapreke. Spodbujanje podjetništva na lokalni ravni ima $v$ primerjavi z državno ravnjo prednost, saj so podporne dejavnosti lahko prilagojene za posebne potrebe podjetij $\vee$ lokalnem okolju. Za lokalno skupnost je pomembno, da ima že $v$ uspešnih podjetjih določeno 
tehnološko infrastrukturo, ki lahko nastopa kot neke vrste inkubator za nove razvojne enote. Tako se lokalna skupnost lahko osredini na tehnologije, ki obstoječo bazo dopolnjujejo in razvijajo naprej. S preventivno strategijo ohranja konkurenčnost obstoječih podjetij in jim pomaga, da uporabijo novo tehnologijo v oblikovanju in produkciji proizvodov (Glas, 2000, str. 106).

Pohleven (2000, str. 244-245) definira tehnološki park kot zaokrožen kompleks, $v$ katerem poleg tehnoloških centrov delujejo tudi uveljavljena srednja in velika podjetja. Omogoča jim najem večjih površin po tržnih cenah, prototipno proizvodnjo in podjetjem ne postavlja časovne omejitve bivanja. Osredinja se na proces tehnologije, poudarja pa tudi sodelovanje raziskovalnih in znanstvenih institucij s podjetji. Naša definicija se od tuje razlikuje le $v$ subvencioniranem najemu prostora in časovni omejitvi bivanja. Omenjena razlika je razumljiva, saj zaradi nerazvitosti in predvsem majhnega števila inkubatorjev $v$ naši državi tehnološki parki delno funkcionirajo tudi kot inkubatorji. Ker država prostor in storitve subvencionira, ne morejo biti časovno neomejeno na razpolago samo majhnemu številu podjetij v parku.

Namen tehnoloških parkov in drugih instrumentov za podporo novim podjetjem je ustanavljanje in spodbujanje nadaljnje rasti podjetij. Povezujejo in spodbujajo sredstva lokalnih skupnosti ter izobraževalnih in raziskovalnih institucij za doseganje višje gospodarske rasti in vitalnosti območja. Ustanovitelj tehnološkega parka si želi lokacijo blizu univerze zaradi večje možnosti komercializacije znanstvenih odkritij, obenem pa želi vplivati na razmišljanje študentov ter privabiti študente in fakultete. Prizadeva si za uporabo in uvajanje znanja, ki ga fakultete razvijajo $v$ obliki patentov in tehnoloških ved. Tehnološki parki, ki se razlikujejo po obliki, vsebini in uspehu, so bili dobro sprejeti ter vzpostavljeni $\checkmark$ številnih najbolj razvitih državah. Velikost parka in objektov je različna, saj park meri od nekaj hektarjev do velikosti, ko postane raziskovalno mesto - tehnopolis (Lalkaka in Bishop, 1996, str. 65-66).

Osnova za regionalni razvoj je krepko povezana z gospodarstvom, ki temelji na znanju. Kot dodajajo Eghbal in drugi (2003, str. 325), strokovnjaki vse bolj prikazujejo pomen regionalnih inovativnih kultur $\vee$ javnem, zasebnem in neprofitnem sektorju. $\vee$ inovacijah in podjetništvu vidijo osnovo za ekonomske spremembe, ki so usmerjene k regionalni blaginji. Inovacije ustvarjajo nove tehnologije z mobilizacijo socialnih in tehničnih idej, kjer podjetniki delujejo kot agenti sprememb. Ameriški in evropski raziskovalci poudarjajo pomen, ki ga imajo tehnološki parki za lokalni in regionalni razvoj. S svojim delom zadržujejo človeške vire in druge zmogljivosti $\vee$ regionalnem okolju in tako ustvarjajo 
Janez Zore

Je predlagano število pokrajin primerna

zasnova za uravnotežen regionalni razvoj?

delovna mesta in dobiček. Še pomembnejše je, da ustvarjajo vrsto novih izdelkov in storitev, s katerimi se utrjuje gospodarski pomen področja, ki je tako vsaj delno zaščiteno pred različnimi neugodnimi pretresi $v$ gospodarstvu. $K$ temu je treba dodati, da s svojo dejavnostjo in oblikami pomoči vplivajo tudi na pestrost in raznolikost podjetniške dejavnosti na določenem regionalnem oz. lokalnem področju.

Razlogi za nastanek tehnoloških in znanstvenih parkov so različni. Cilji, ki jih želijo doseči, so odvisni od ustanoviteljev, lastnikov oziroma večinskih lastnikov. Ti lahko s svojo vlogo odločilno oblikujejo cilje parkov. Tehnološki ali znanstveni park je sredstvo, s pomočjo katerega univerza sodeluje z okolico. Za univerzo je lahko to tudi dodaten finančni vir (najemnine, svetovalne storitve najemnikom, oprema, investicije tveganega kapitala), z njim pa si univerza lahko ustvarja tudi ugled. Pri tem velikokrat sodeluje tudi država s podpornimi programi za pospeševanje oziroma povečanje prenosa tehnologije. Dejavnost parka je temu ustrezna in najemniki delujejo na področjih, na katerih dosega univerza raziskovalno odličnost. Take oblike znanstvenega oziroma tehnološkega parka so pogoste $\vee$ ZDA, najdemo pa jih tudi v Evropi. Tako kot za ustanovitev inkubatorja tudi za uspešno ustanovitev in delovanje tehnološkega in znanstvenega parka ni enostavnega modela, ki bi splošno popisal vse potrebne lastnosti oziroma sestavine parka. Pri vsakem posebej je treba preučiti omenjene ključne dejavnike in v skladu z njimi organizirati delovanje parka in centra. Po evropskih kriterijih mora imeti tehnološki park za uspešno delovanje zaledje okrog 300.000 prebivalcev, eno ali dve univerzi in nekaj nadnacionalnih družb (Pohleven, 2000).

Tehnološki parki razvijajo podporno okolje, kjer s promocijo, storitvami in z infrastrukturo motivirajo tehnološki podjetniški potencial $\vee$ regiji. $S$ premišljenimi shemami pomoči spodbujajo $k$ ustanavljanju in pomagajo pri rasti in delovanju družb z visokim tržnim potencialom. Na ta način prispevajo k preoblikovanju lokalnega gospodarstva, vpeljevanju in ohranjanju kakovostnejših delovnih mest in $k$ večji konkurenčnosti inovativnega podjetništva $v$ regiji. Podjetjem pomagajo pri njihovem razvoju tudi z vzpostavljanjem sinergij in povezav med domačim in tujim raziskovalnim, tržnim in podjetniškim okoljem. Neformalne in formalne povezave z raziskovalnim in razvojnim okoljem omogočajo izmenjavo znanja in tehnologij ter njihovo hitrejšo tržno uveljavitev.

Znanstveni in tehnološki parki so bili v zadnjih letih obravnavani kot ena izmed gonilnih sil znanosti, tehnologije in inovacij nacionalnih sistemov, večinoma $\vee$ razvitih državah. Klasični koncept znanstvenega in tehnološkega 
parka temelji na prednostih koncentracije ustvarjalnih naporov, formalnih in neformalnih povezav, mrež, zbranih na enem mestu $v$ regiji, ter prisotnosti pomembnih osebkov na trgu, kot so univerza, raziskovalni centri in tehnološka podjetja. Do sedaj se je v EU razvila že vrsta mehanizmov, ki lajšajo povezave med inkubatorji in znanstvenimi ter tehnološkimi parki. Ti se nagibajo $k$ povezavam, saj jim prinašajo prepotrebno znanje in izkušnje. $\vee$ preteklosti so bili glavni mehanizmi za izmenjavo izkušenj sestanki $\vee$ organizaciji nacionalnih in mednarodnih združenj in so vključevali predvsem menedžment tehnoloških in znanstvenih parkov. $V$ zadnjem času se je interes po povezovanju in mreženju povečal, predvsem glede mreženja človeškega kapitala. Prav tako se novi znanstveni in tehnološki parki že $v$ predlogih za ustanovitev nagibajo $k$ povezovanju in prikažejo možnosti za povezovanje z drugimi parki. Pogosto se zgodi, da so mreže vzpostavljene brez jasnih ciljev, povezanih s potencialnimi ugodnostmi za njihove uporabnike ali z ravnijo izvedbe, ki naj bi jo mreža dosegla. Te so ustanovljene na osnovi ideje, da je že samo sodelovanje $v$ mreži pozitivno, kljub temu da mreža nima jasnega cilja, kakšne informacije bi sodelujoči izmenjevali in kdo naj bi v izmenjavi informacij sodeloval, kar pa na izrabo mreže slabo vpliva.

\section{Aktivnosti slovenske vlade na razvojnem področju v Sloveniji}

Slovenska vlada se zaveda položaja naše države $v$ razmerju do razvitih držav EU. Če ga želi izboljšati in se jim približati, mora povečati globalno konkurenčnost. Do nje lahko pridemo na podlagi korenitih strukturnih reform, ki bodo rešile temeljne razvojne težave in premagale odpore do hitrejših družbenih sprememb. Temeljni podlagi za državni razvoj sta Strategija razvoja Slovenije ( $v$ nadaljevanju SRS) in Državni razvojni program (v nadaljevanju DRP). Slednji je izvedbeni dokument SRS in se osredinja na uspešno realizacijo investicijskorazvojnih prioritet, medtem ko je SRS konceptualni okvir za razvoj države v obdobju finančne perspektive EU 2007-2013.

Pozornost slovenske vlade bo pri izvajanju regionalne strategije osredinjena na pet ključnih razvojnih prioritet. Sestavljene so tako, da v koherentne celote povezujejo ukrepe iz pristojnosti več resorjev, in sicer tiste, ki jih je mogoče najhitreje izvesti in ki lahko kratkoročno največ prispevajo $k$ doseganju ciljev strategije kot celote. Z osredinjanjem na skupne razvojne prioritete bo dosežena tudi večja stopnja koordinacije vlade, kar je pogoj za uresničenje 
potrebnega strukturnega premika v razvojni politiki. Po mnenju vlade sta konkurenčno gospodarstvo in hitrejša gospodarska rast najhitreje izvedljivi in hkrati lahko kratkoročno največ prineseta $k$ doseganju ciljev kot celote. $S$ tem namenom je bila tudi postavljena kot prioriteta regionalne strategije. Tu je mišljena predvsem mreža inkubatorjev, tehnoloških parkov in poslovnih con, ki bodo skupaj ter $\vee$ povezavi z znanjem in razvojem lahko ponudili gospodarstvu tiste storitve, ki jih najbolj potrebuje na različnih razvojnih stopnjah - od ideje podjetja do razvoja visokih tehnologij, novih materialov in podobno. Razvojna infrastruktura bo $v$ prostoru razpršena in usmerjena tja, kjer bo koncentracija poslovnih dogodkov omogočala hiter začetek delovanja in hitre učinke. Predvidena je tudi razpršenost visokošolskega prostora oziroma ustanavljanje visokošolskih središč in sicer takšnih, ki bodo sledila razvojnim priložnostim Slovenije in gospodarstva $v$ regionalnih razvojnih središčih.

Izboljšanje konkurenčnih sposobnosti podjetij se poveča z razvojem gospodarstva in inovativnosti. $\vee$ tem primeru gre lahko za razvoj in delovanje podjetniških inkubatorjev in tehnoloških parkov, vzpostavitev slovenskega centra za prenos inovacij vključno z borzo inovacij, promocijo in uvajanje evropskega modela odličnosti ter drugih modelov, spodbujanje aplikativnih razvojnih projektov podjetij, ukrepe različnih politik za pospeševanje podjetniških vlaganj $\vee$ raziskave in razvoj ter spodbude za ustanavljanje domačih in tujih visokotehnoloških in inovativnih podjetij ter investiranje v človeške vire.

\section{Premik na reginalnem področju v Sloveniji}

V juniju 2006 so bile sprejete ustavne spremembe ${ }^{2}$, ki bodo omogočile regionalizacijo Slovenije. Gledano s sistemskega vidika bodo pokrajine kot nova oblika upravnoteritorialne strukture prinesle številne spremembe $\vee$ drugih delih družbenega sistema - v pravnem redu oz. zakonodaji, javnih financah, državni upravi, položaju občin, na delovnem področju posameznih ministrstev, v čezmejnem sodelovanju lokalnih skupnosti, $v$ mednarodnih razmerjih in povezavah ter tudi v položaju državljanov (Vlaj, 2006b). Po mnenju Strmšnika (2004, str. 140) Ustavni zakon o spremembah sam po sebi ne prinaša konkretnih rešitev, daje pa možnost za premik z mrtve točke. S spremembo ustave, ki bo omogočila oblikovanje pokrajin $v$ skladu z zakonom, je bil torej sprožen pris-

2 Ustavni zakon o spremembah 121., 140. in 143. člena Ustave RS, Uradni list RS, št. $68 / 2006$. 
top oblikovanja pokrajin od zgoraj navzdol, pri čemer pa bo smiselno upoštevati predvsem voljo občin, kar predvideva tudi ustava. Volja občin mora biti tu temelj za učinkovitost procesa decentralizacije, saj brez doseženega teritorialnega soglasja decentralizacija lahko zgreši svoj smisel.

Sprejete ustavne določbe so tudi podlaga za oblikovanje zakonov ${ }^{\mathbf{3}}$, ki bodo omogočili decentralizacijo oblastnih funkcij in prenos upravljanja pomembnega dela javnih zadev $z$ državne na pokrajinsko raven. Tako je naslednja stopnja $v$ procesu vzpostavljanja pokrajinske samouprave priprava normativnih podlag za njihovo delovanje. Te morajo temeljiti na načelih, ki so $v$ slovenski pravni red vgrajene z Evropsko listino lokalne samouprave in opredeljujejo sestavine samoupravnosti samoupravnih lokalnih skupnosti, ki jih poznamo že iz procesa reforme lokalne samouprave. To pomeni, da so vrednote in načela lokalne samouprave hkrati vrednote in načela pokrajinske samouprave (Gotovac, 2006, str. 23).

Eno izmed ključnih vprašanj je torej velikost prihodnjih pokrajin, saj je pri tem vprašanju mogoče uporabiti različna regionalizacijska načela, kriterije in temu primerno regionalizacijo oziroma zelo različno število regij. Rojevajo se zamisli o številu možnih območij pokrajin, ki se giblje med 4 in 30 regij. Plut (2004, str. 34) meni, da kriterij geografske raznolikosti in regionalne pripadnosti prebivalk in prebivalcev nakazuje členitev na večje število pokrajin (več kot 10), razvojni, nacionalno-strateški in pričakovani globalizacijski izzivi pa členitev na manjše število pokrajin (manj kot 10). Po strokovnih kriterijih za geografsko, prebivalstveno in urbano sestavo Slovenije naj bi bil s slovenskega vidika kot najprimernejši ovrednoten predlog členitve na 8 , srednje velikih pokrajin. Glede na geografsko, poselitveno in gospodarsko sestavo Slovenije, sodobne evropske regionalizacijske težnje in predvidene široke naloge pokrajine bi členitev na osem pokrajin glede na razmerje med učinkovitostjo in stroški po mnenju večine strokovnjakov omogočala najbolj smotrno in optimalno izpolnjevanje zahtevnih avtonomnih nalog in opravil (Vlaj, 2006b). Šmidovnik (2004, str. 15) ob tem argumentirano navaja (z njim se strinjajo tudi Vlaj, Plut, Prašnikar), da so študije ${ }^{4}$ pokazale, da bi moralo biti $\vee$ Sloveniji ob optimalnem izboru šest do osem pokrajin. To pomeni, da večje število pokrajin, med katerimi bi bile tudi

3 Vlada je že podala skupek predlogov zakonov o pokrajinah, ki so že usklajeni medresorsko in tudi s poslanskimi skupinami. To so: predlog zakona o financiranju pokrajin, predlog zakona o pokrajinah in predlog zakona o volitvah v pokrajinah. Predlog zakona o ustanovitvi pokrajin pa bo vlada pripravila po podrobni preučitvi mnenj občinskih svetov k predlogu vlade RS za določitev območij pokrajin, njihovih sedežev in imen.

4 Dokumenti in študije o pokrajinah v Sloveniji 2000-2004, Ministrstvo za notranje zadeve, Ljubljana, 2004. 


\section{Janez Zore \\ Je predlagano število pokrajin primerna \\ zasnova za uravnotežen regionalni razvoj?}

take s precej manj kot 100.000 prebivalci, ne bi zmoglo opravljati predvidenih obširnih in zahtevnih nalog pokrajin, zlasti tistih regionalnega pomena in tistih, ki naj bi jih pokrajine opravljale za državo. To pa bi vplivalo tudi na zamisel o pokrajini kot ustrezno zmogljivi lokalni skupnosti za prevzem zahtevne vloge splošnega nosilca javnih nalog $v$ vmesnem prostoru. To bi zniževalo vlogo pokrajin, podobno kot veliko število premajhnih občin znižuje vlogo občin in s tem tudi vlogo naše lokalne samouprave. Obstoječe občine so premajhne, država pa je prevelika, da bi uspešno opravljala največji del tistih nalog, ki najbolj zanimajo državljane.

Slovenska vlada je konec maja letošnjega leta $v$ dnevnih časopisih in tudi na spletni strani vladne službe za lokalno samoupravo in regionalno politiko objavila predlog razdelitve Slovenije na 14 pokrajin. Predlagano število naj bi bil zgornji doseg števila pokrajin, s čimer se bolj ali manj strinjajo vse politične stranke. Ob tem vlada ne bi nasprotovala, če bi se med usklajevanjem število pokrajin zmanjšalo. Kljub vsemu bo glede zakona o območju pokrajin potreben kompromis, ki bo tudi politično usklajen, saj ne smemo pozabiti, da se bo zakon v parlamentu sprejemal z dvotretjinsko večino navzočih poslancev. Ob tem so bili občinski in mestni sveti pozvani $k$ javni razpravi, da $\vee$ roku 60 dni podajo svoja mnenja. Večina občinskih svetov je načelno podprla vladni predlog, poleg tega pa podala tudi dodatne predloge. Mednje sodijo predlogi o spremembi imena in sedeža pokrajine ter predlogi za zmanjšanje števila pokrajin. Manjši del občinskih svetov pa se je na vladni predlog odzval negativno. Razlogi za to so $v$ premalo dodelani pokrajinski zakonodaji in bojazni, da bi ustanovitev pokrajin povzročila še večjo razliko pri razvoju posameznih regij. Zagotovilo vlade je, da bo vsa mnenja in predloge občinskih svetov podrobno preučila in se do njih opredelila, tako pridobljena spoznanja pa bo upoštevala pri pripravi predloga zakona o ustanovitvi pokrajin.

Ob tem predlogu se je Vlaju (2006b) porodil upravičen strokovni dvom o možnosti kakovostnega opravljanja upravnih in drugih funkcij, zlasti razvojnih in storitvenih. $V$ primeru členitve Slovenije na 14 pokrajin bi bilo celo $v$ šestih pokrajinah manj kot 100.000 prebivalcev, kar je po mnenju večine evropske strokovne javnosti spodnja meja za regionalno razvojno uspešnost. Večje pokrajine $s$ prebivalstveno močnejšim zaledjem $v$ veliki meri preprečujejo, da bi se enostransko razvijalo le regijsko središče, kar je objektivna nevarnost v majhnih pokrajinah. Zaradi večje gospodarske in finančne moči pa so večje pokrajine trdnejši in bolj samozavesten sogovornik državi (Plut, 2007, str. 16-17). 
Obstajajo tudi drugi modeli členitve, ki imajo svoje prednosti in slabosti. Plut (2004, str. 23-24 ter tudi 2007, str. 16) meni, da vplivi globalizacije z vidika potencialne gospodarske uspešnosti podpirajo oblikovanje večjih, razvojno in prebivalstveno dovolj močnih regij. Večje regije namreč dosegajo kritično količino regionalnih virov, torej dovolj velike gospodarske, človeške, infrastrukturne in druge lastne razvojne zmogljivosti za brezkompromisno globalno tržno tekmovanje regij EU in sveta. Večje pokrajine z močnejšimi regionalnimi središči oziroma s povezano mrežo mest so geopolitično, razvojno strateško ter z vidika ohranjanja in krepitve nacionalne identitete eden od odločujočih dejavnikov za uravnavanje gravitacijske privlačnosti velikih sosednjih mest (Trst, Gorica, Zagreb, Gradec, Celovec, Reka). Po drugi strani pa so z vidika vplivov sodobnega regionalizma, zlasti regionalne enakopravnosti, upravičene težnje in želje približanja upravnih storitev države prebivalcem regije, kar z vidika območja regij pomeni njihovo večje število. Sodobni izzivi sonaravnega razvoja, rabe regionalnih virov in regionalizmi (skupaj z občutkom pripadnosti prebivalk in prebivalcev določenemu ozemlju oz. regiji) in želja po približanju upravnih in drugih nalog praviloma poudarjajo pomen členitve na manjša, tudi fizičnogeografsko ter pokrajinsko-ekološko sklenjena območja.

Plut (2004, str. 28) in Vlaj (2006b) menita, da bi glede na geografsko, poselitveno in gospodarsko sestavo Slovenije, sodobne evropske regionalizacijske težnje in predvidene široke naloge pokrajine členitev na osem pokrajin omogočala najbolj smotrno, optimalno izpolnjevanje zahtevnih avtonomnih nalog in opravil glede na razmerje med učinkovitostjo in stroški. Vlaj (2006b) tu dodaja, da so predlagana pokrajinska središča $\vee$ državnih razvojnih programih opredeljena kot žarišča regionalnega razvoja. Predlagana rešitev razdelitve Slovenije na osem pokrajin z regionalnimi centri višje stopnje in/ali s povezano razvojno močno mrežo manjših regionalnih centrov (mest) je tudi ustrezen odgovor na pričakovani gravitacijski pritisk bližnjih močnejših središč sosednjih držav.

\section{Sklepne ugotovitve}

Sprejete ustavne spremembe na področju lokalne samouprave bodo omogočile, da bomo tudi $\vee$ Sloveniji prišli do vmesne stopnje med "veliko" državo in "malimi" razkropljenimi občinami. S tem se bo tudi v naši ureditvi odprla pot za proces decentralizacije in uveljavljanje načela subsidiarnosti, hkrati pa bo narejen ključni korak k uresničevanju skladnega gospodarskega in regionalnega 


\section{Janez Zore \\ Je predlagano število pokrajin primerna \\ zasnova za uravnotežen regionalni razvoj?}

razvoja. Pokrajine bodo olajšale povezavo Slovenije z EU, predvsem pri uspešnejšem pridobivanju sredstev EU, hkrati pa bodo okrepile tudi čezmejno sodelovanje regionalnih skupnosti. Ob predlagani členitvi Slovenije na 14 pokrajin bo kar 13 od 14 predlaganih pokrajin mejilo na sosedne države in s tem na možnost sodelovanja z uspešnimi in močnimi regijami sosednih držav. Najmanjša in hkrati tudi najbolj zaostala Zasavska pokrajina ne bi imela te možnosti. Ta je "zasidrana" oziroma se razprostira v jedru naše države, tako da bi bila že poleg trenutnih težav, ki jo tarejo, in zaostalosti za slovenskim povprečjem, deležna primanjkljaja še iz naslova čezmejnega sodelovanja in bi ji bila s tem onemogočena možnost ustreznega razvoja.

Vlada bi se pri določitvi pokrajinske zakonodaje morala bolj opirati na predloge strokovne javnosti. Nedvomno bo težko uskladiti najrazličnejše interese in politične pritiske, ki se kažejo ob začeti javni razpravi. Vsaj tokrat bi morali prevladati razvojni interesi nad drugimi, kajti predlagano število 14 pokrajin je pretirana številka, saj želimo imeti kadrovsko in kapitalsko močne pokrajine. Le takšne se bodo lahko kosale s primerljivimi in regijsko močnimi pokrajinami sosednjih držav. Prizadevanja za regionalizacijo namreč potekajo že vse od osamosvojitve dalje, tako da bi bilo bolj smotrno ustanoviti večje pokrajine. Le takšne bi predstavljale hrbtenico za reševanje zahtevnih avtonomnih nalog in opravil. $\vee$ skladu s sedanjim vladnim predlogom za ustanovitev pokrajin bi povprečna slovenska pokrajina zajemala približno 140.000 prebivalcev, kar pa je manj, kot določajo evropski kriteriji. Poleg tega je evropsko mnenje tudi, da spodnja meja za uspešen regionalni razvoj nikakor ne bi smela biti nižja od 100.000 prebivalcev. Ob trenutnem vladnem predlogu za delitev Slovenije na 14 pokrajin, bi jih kar 6 imelo manj prebivalcev od te meje, Zasavska pokrajina pa kot najmanjša le slabo polovico te vrednosti, približno 46.000 prebivalcev.

Gospodarsko uspešne regije spodbujajo razvoj znanosti in tehnologij, zlasti na področju aplikativne raziskovalne dejavnosti, ustvarjanja inovativnega podjetništva in komercializacije visoko tehnoloških proizvodov in storitev. Želja Slovenije je namreč, da postane regionalno razvita in s tem konkurenčnejša na globalnem trgu. Aktivna regionalna politika, ki bi omogočila hitrejše dohitevanje bolj razvitih slovenskih in evropskih regij, bi morala upoštevati prednosti in jih usmeriti $v$ doseganje določenih ciljev. Za ta namen moramo ustvariti učinkovite pogoje, v katerih se bo čim več ljudi odločalo za podjetništvo, podjetja pa bodo kakovostno rasla. To še posebej velja za tehnološko podjetništvo, ki je eden nujnih pogojev odpiranja kakovostnih delovnih mest ter doseganja visoke dodane vrednosti in posledično blaginje slovenskega prebivalstva. 
$V$ zadnjih dveh desetletjih imajo pri soustvarjanju uspešnega, na znanju temelječega podjetništva, pomembno vlogo tudi tehnološki parki, ne le kot ponudniki kakovostnih vsebinskih in infrastrukturnih storitev podjetjem, temveč tudi kot pomemben partner državnim in lokalnim institucijam pri udejanjanju strategij gospodarskega razvoja. Poleg tega so tehnološki parki pomembni akterji na področju pospeševanja podjetništva, tehnološkega razvoja regij, zaposlovanja in globalnega poslovanja. Tehnološki parki so dokazano učinkovita podpora malim in srednje velikim podjetjem. Podjetjem $v$ zagonu nudijo prostor in svetovalne storitve, poleg tega pa tudi velike možnosti za raziskovalno dejavnost.

Sodeč po raznih intervjujih in člankih lahko tudi pričakujemo, da bo vsaka od pokrajin želela imeti tudi svoje lastno raziskovalno središče. Tehnološki park pomeni koncentracijo raziskovalcev, profesorjev in skupek drugih strokovnjakov, kar omogoča povezavo med raziskovanjem in gospodarstvom. Za uspešno in učinkovito delovanje in $s$ tem pospeševanje regionalnega razvoja tehnološki parki med drugim potrebujejo tudi redna univerzitetna središča. V Sloveniji so trenutno ustanovljene tri univerze, ki predstavljajo skupek znanstvenikov in strokovnjakov, združenih na določenem regionalnem območju. Iz navedenega lahko zaključimo, da z ustanovitvijo večjega števila manjših in s tem šibkejših pokrajin ne bi zadostili pričakovanim ciljem uveljavljanja naše države in regij na skupnem evropskem in svetovnem trgu.

Mag. Janez Zore je diplomiral na Fakulteti za pomorstvo in promet. Po diplomi je nadaljeval študij na Fakulteti za upravo, kjer je leta 2006 specializiral in nato konec leta 2007 magistriral s področja uprave. V letu 2002 se je zaposlil na Upravni enoti v Novem mestu. Od leta 2004 je zaposlen na Mestni občini Novo mesto, kjer opravlja naloge občinskega inšpektorja. 


\section{Janez Zore \\ Je predlagano število pokrajin primerna \\ zasnova za uravnotežen regionalni razvoj?}

\section{Literatura in viri}

- Draft Report on the current situation concerning regionalization and the prospects for developing regional self-government in Council of Europe member states. Strasbourg, 2006.

- $\quad$ Eghbal, M. K. Keshmiri, M. Asghari, K. Roustazadeh, E.: Incubators and Universities: How to Overcome Cultural Barriers against Innovation. XX IASP World conference on science and technology parks, Lisboa, 2003, str. 324-329.

- Glas, M.: Sodobni podjetniški pristop k lokalnemu-regionalnemu razvoju. Podjetništvo - izziv za 21. stoletje. 2000b, Gea College, Ljubljana, str. 95-117.

- Gotovac, V.: Priprava zakonov o pokrajinah. V: Vlaj, S. (ur.): Posvet o regionalizaciji uvedba pokrajin. Inštitut za lokalno samoupravo pri Fakulteti za upravo, Ljubljana, 2006, str. 23-28.

- Grafenauer, B.: Lokalna samouprava na Slovenskem, Teritorialno-organizacijske strukture. Univerza v Mariboru, Pravna fakulteta, Maribor, 2000

- Lajh, D.: Evropeizacija in regionalizacija. Fakulteta za družbene vede, Ljubljana, 2006.

- Marques, J. P. C., Caraca, J. M. G., Diz, H.: The macro in micro context of business incubators: A preliminary approach to incubation process. XX. IASP World conference on science and technology parks, Lisboa, 2003, str. 113-121.

- Pohleven, P.: Podjetniški inkubatorji in tehnološki parki. Podjetništvo - izziv za 21. stoletje. 2000, Gea College, Ljubljana, str. 243-264.

- Plut, D.: Zasnova členitve Slovenije na pokrajine s pomočjo trajnostno sonaravnih izhodišč. V: Vrišer, I. (ur.): Pokrajine v Sloveniji. Vlada Republike Slovenije, Služba za lokalno samoupravo, Ljubljana, 1999, str. 65-73.

- $\quad$ Plut, D.: Načela, kriteriji in regionalizacija Slovenije z vidika členitve na pokrajine. V: Vlaj, S. (ur.): Pokrajina: druga raven lokalne samouprave. Inštitut za lokalno samoupravo pri Fakulteti za upravo, Ljubljana, 2004, str. 21-36.

- $\quad$ Plut, D.: Regionalna razdelitev Slovenije. Štirinajst pokrajin - primeren odgovor na izzive 21. stoletja? Delo, sobotna priloga. Ljubljana, 21. 4. 2007, str. 16-17.

- Prašnikar, A.: Naloge pokrajin. V: VLAJ, S. (ur.): Pokrajina: druga raven lokalne samouprave. Inštitut za lokalno samoupravo pri Fakulteti za upravo, Ljubljana, 2004, str. 37-51.

- Ravbar, M.: Oblikovanje pokrajin in njihova vloga pri regionalnem razvoju. V: Vrišer, I. (ur.): Pokrajine v Sloveniji. Vlada Republike Slovenije, Služba za lokalno samoupravo, Ljubljana, 1999, str. 96-102.

- Rebernik, M. Tominc, P. Pušnik, K.: Počasne spremembe podjetniške stvarnosti. Univerza v Mariboru, Ekonomsko-poslovna fakulteta, Maribor, 2007.

- Strmšnik, I.: Pokrajine v Sloveniji in Evropska unija. V: VLAJ, S. (ur.): Pokrajina: druga raven lokalne samouprave. Inštitut za lokalno samoupravo pri Fakulteti za upravo, Ljubljana, 2004, str. 135-146. 
- Šmidovnik, J.: Ustavna in zakonska zamisel pokrajine. V: VLAJ, S. (ur.): Pokrajina: druga raven lokalne samouprave. Inštitut za lokalno samoupravo pri Fakulteti za upravo, Ljubljana, 2004, str. 11-20.

- Vlaj, S.: Lokalna samouprava v Sloveniji centralizem ali decentralizacija. http://www.ifimes.org/. 11. 10. 2005.

- Vlaj, S.: Pokrajine in decentralizacija Slovenije. V: VLAJ, S. (ur.): Posvet o regionalizaciji - uvedba pokrajin. Inštitut za lokalno samoupravo pri Fakulteti za upravo, Ljubljana, 2006a, str. 7-15.

- Vlaj, S.: Pokrajine in decentralizacija Slovenije. http://www.ifimes.org/. 17. 10. 2006b.

- Zouain, D. M. Plonsky, G. A. Rogero, J. R. Vedovelo, C.: Public policies for regional development - the case of the technology park of Sao Paolo. XX IASP World conference on science and technology parks, Lisboa, 2003, str. 290-296. 
Janez Zore

Je predlagano število pokrajin primerna

zasnova za uravnotežen regionalni razvoj?

SUMMARY

\section{IS THE PROPOSED NUMBER OF REGIONS A SUITABLE BASELINE TO BALANCED REGIONAL DEVELOPMENT?}

All countries are coping with unequally developed territory and thus regions differentiate in many respects. Influence on different developing possibilities of a specific area is shown mainly by different availability of natural, economical, social and other resources. The reduction of regional differences should not be left only to market rules. Every modern country tries to abolish regional unbalances on its territory and strengthen economic and social connections. With this purpose countries carry out their own regional policy within which they encourage harmonious regional development of their economy. In the areas where there is a strong concentration of capital, vacancies and services migration are raising many problems, especially communal, social and environmental, while the surrounding areas are emptying and their culture is declining.

In the last decades the world economy has experienced extremely high development. Countries have moved from industrial to information society. Mental work as a dominant part of employee's activities has mainly replaced physical work. Characteristics of today's modern world are fast change, facilitating of scientific and technological development and competition, with demands for higher education and learning level. But there is no general acknowledgment that this kind of development creates also new psychological demands which are result of these changes. Such development requires greater ability for innovations, selfcontrol and personal responsibility.

Small and medium enterprises are becoming from year to year a more important part of economy, becoming one of the most perspective economy branches. Encouraging the growth of small and medium enterprises is crucial for creating possibilities for further economic development. At the same time it considerably contributes to creating new vacancies and is one of basic factors for harmonious regional development. Regional structural policy and harmonious development are important guidelines of EU policy as well as for individual countries. Differences among individual regions within EU member states are growing. Only the regions which take care for their own development of small economy and innovations, are developing. 
Small and medium enterprises are crucial for development and image of entire village, community and region. They bring new information and knowledge and change people's mentality. Above all their influence is very important for development of small local areas which do not offer real chances for large enterprises. For facilitating development of small and medium enterprises the countries establish institutions which support activity for their development, besides forming different types of measures and mechanisms. Flexible institutions are necessary for successful activity and completion of enterprises' and areas' needs. Partners with their long term association and connection of available potentials considerably contribute to successful and facilitated development of small and medium enterprises. In current circumstances foreign initiatives are not suitable for imitation because they must adapt to concrete circumstances.

Economy experts are increasingly pointing to the importance of a regional innovative culture in the private, public, and non-profit sectors as a primary basis for prosperity in the knowledge-based economy. They see innovation and entrepreneurship as the engines for economic change aimed at regional prosperity. Innovation is defined as the creation of new technologies through mobilizing social or technical ideas towards commercialization where entrepreneurs act as agents of change. For developing countries, the main question is how to create and promote a culture of regional innovation. In the paper the author explores the possibilities how universities and incubators can overcome the cultural and educational barriers for innovation, especially in developing countries.

Lately, the scientific and technology parks have been considered as one of the science, technology and innovation systems engine of the nation, mainly in developed countries. The classical conceptualisation of science and technology parks is based on benefits of concentrating creative efforts and formal or informal networks, with support of actors like university, research centres and technology based enterprises.

Technological parks and other instruments for supporting the new enterprises are established with the purpose of establishing and encouraging further growth of enterprises. They are connecting and encouraging resources of local self-governments, knowledge and research institutions for gaining a higher economy growth and area vitality. Organization and strategic orientation of technological park is a complex task and requires comprehensive studies. According to the European criteria a technological 
Janez Zore

Je predlagano število pokrajin primerna

zasnova za uravnotežen regionalni razvoj?

park should have for its successful activity a background of around 300.000 inhabitants.

American and European researchers emphasize the importance of technological parks for local and regional development. With their work they retain human resources and other performance factors in regional environment and so create vacancies and profit. Even more important is that they create new products and services and thus fortify the economic importance of area. Furthermore, with their activity and support they also influence upon variety and different activities of enterprises in a specific regional or local area.

Technological parks develop support environment where by promotion, services and infrastructure they motivate entrepreneur's technological potential in the region. With help schemes they encourage establishment and they help the growth and activity of societies with high commercial potential. So they contribute to the transformation of local economy, implementation and maintaining qualitative vacancies and greater innovative entrepreneurs' competition in the region. They help enterprises in their development also with establishment of synergy and connections between homeland and foreign researching, commercial and enterprises environment. Official and unofficial connections with researching and developing environment allow exchange of knowledge and technologies and their faster acceptance in the market.

Adopted constitutional changes in the field of local self-government will allow Slovenia to achieve double-level local self-government. This will open a path for the process of decentralization and put in force the principle of subsidiarity. At the same time, crucial steps to realisation of harmonised regional development will be taken. Regions will facilitate connection of Slovenia with EU by enabling to gain the EU funds. They will also strengthen cross-border cooperation of regional communities.

When defining region legislation the government should rely more on proposals from experts. The proposed number of 14 regions is too large, if we wish to have professional and financial strong regions. Only such regions could cope with comparative and regional strong regions of neighbouring countries. It would be better to establish larger regions which could present a backbone for solving complex autonomous tasks and activities. In the current government proposal for establishment of regions an average region would cover 140.000 inhabitants which is less 
than half as determined by the current European criteria. We must consider also the fact that the Slovene central region extremely exceeds the average.

Probably each region will wish to have its own research centre. Technological parks present a concentration of researchers, professors and community of other experts and therefore promote a strong relation between researching and economy. For efficient and effective activity and hereafter facilitating regional development technological parks also need permanent connection to university centres. In Slovenia there are currently three universities which present a group of researchers and experts in a regional area. Therefore it is possible to conclude that with establishment of many smaller and thus weaker regions the expected effective performance of our country and regions on the common European and world market would not be achieved. 